\title{
Description
}

\section{Tetraploid 'Planters Jumbo' Melon Lines C883-m6-4x and 67-m6-100-4x}

\author{
Perry E. Nugent ${ }^{1}$ \\ U.S. Vegetable Laboratory, Agricultural Research Service, U.S. Department \\ of Agriculture, 2875 Savannah Highway, Charleston, SC 29414
}

Additional index words. muskmelon, cantaloupe, Cucumis melo

Lines C883-m6-4x and 67-m6-100-4X are spontaneous tetraploid mutants from the melon cultivar Planters Jumbo (Cucumis melo L.). 'Planters Jumbo' is the result of a series of crosses and "selected generations involving several cultivars and plant introductions. These tetraploid selections were approved for release in 1991 by the Agricultural Research Service, U.S. Dept. of Agriculture, in response to seed industry requests. These $4 \mathrm{x}$ lines can be used as a tool in tetraploid melon research and for $3 \mathrm{x}$ melon production feasibility studies.

\section{Origin}

During Summer 1969, a tetraploid plant $(4 \mathrm{x})(\mathrm{n}=\mathrm{x}=12)$ was found in a field planting of 'Planters Jumbo' melon (Fig. 1) and given the accession number C883-m6-4x. Later, in the fall, another tetraploid plant was recovered from a greenhouse planting of the $2 x$ line 67-1, the parent of 'Planters Jumbo' melon,

Received for publication 25 Feb. 1993. Accepted for publication 6 Aug. 1993. The cost of publishing this paper was defrayed in part by the payment of page charges. Under postal regulations, this paper therefore must be hereby marked advertisement solely to indicate this fact.

'Research Horticulturist. and this mutant was designated 67-m6- 100$4 x$. Chromosome counts of 'Planters Jumbo' and its $4 \mathrm{x}$ offspring confirmed the ploidy levels of these mutant lines (Nugent and Ray, 1992). C883-m6-4x and 67-m6- 100-4X provide a means for developing seedless triploid melons that carry the desirable characteristics of the original $2 x$ cultivar. Such $3 x$ seedless melons have been produced from $4 \mathrm{x}$ and $2 \mathrm{x}$ crosses (Adelberg, 1993).
The lines described are similar and have many parental ('Planters Jumbo') characteristics, such as thick flesh and fleshy placentas. The 4x types differ from 'Planters Jumbo' in that they have larger cells. Leaves, stems, and flowers of $4 x$ types are noticeably larger than their $2 \mathrm{x}$ counterparts. Although each $4 \mathrm{x}$ derivative differs slightly in fruit size, the following characters describe both $2 x$ and $4 x$ melon types. Fruit of $4 \mathrm{x}$ types are rounder and smaller than those of 'Planters Jumbo'. Depending on the environment and culture, fruit of $4 x$ lines have thicker, firmer, higher-quality flesh and fewer (one-fourth to one-half as many) seeds than $2 x$ types (Figs. 2 and 3 ). Fruit of the virescent 4x C879-J2 (H10, Figs. 2 and 3 ) have large stem and blossom scars, which are typical of all $4 \mathrm{x}$ fruit types. The seeds of 2x 'Planters Jumbo' are slightly longer and narrower than $4 \mathrm{x}$ seeds.

Under similar growing conditions, $4 x$ plants differ from their $2 x$ parents. Tetraploid plants 


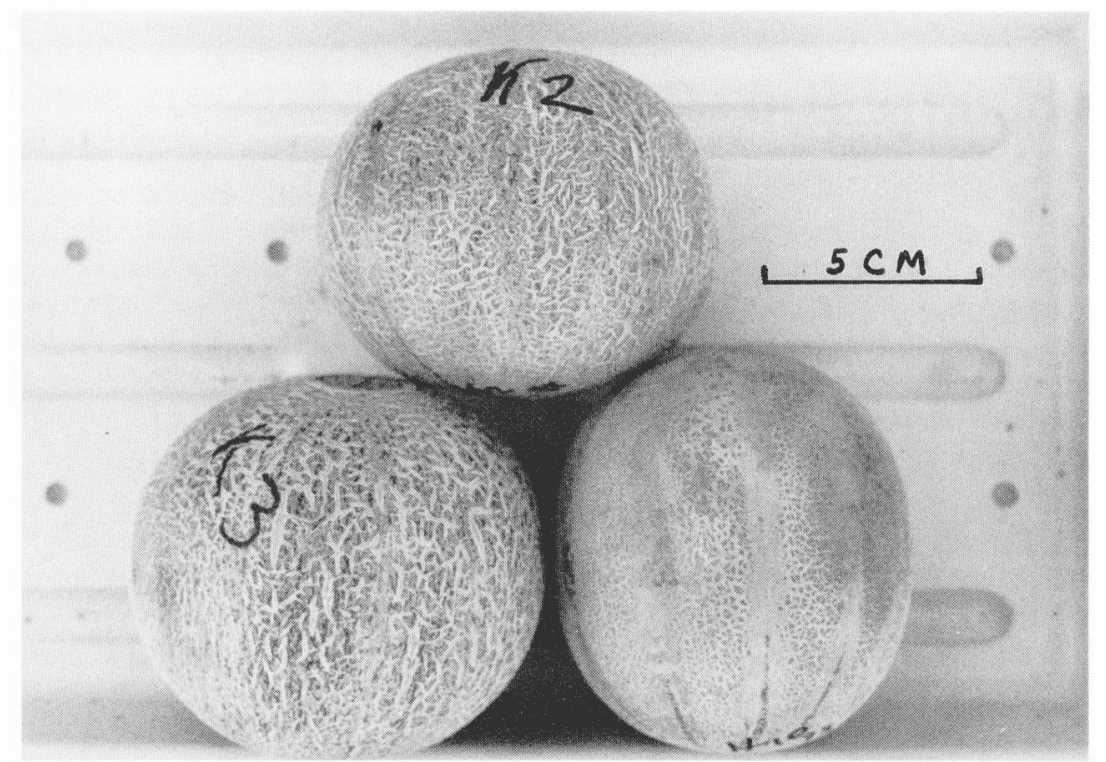

Fig. 2. Side view of C883-m6-4x (K2), 1.4 kg; 67-m6-100-4x (K3), $1.3 \mathrm{~kg}$; and C879-J2-4x (H10), $1.1 \mathrm{~kg}$, melons.

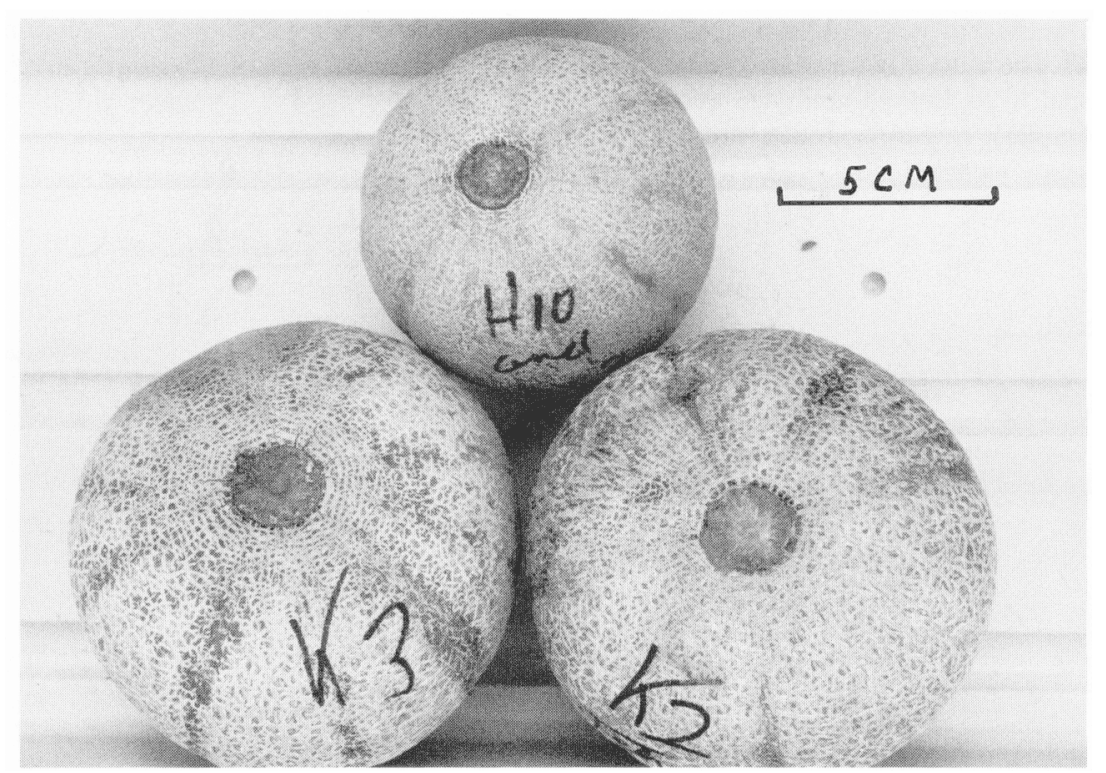

Fig. 3. Top view of C883-m6-4x (K2), $1.4 \mathrm{~kg}$; 67-m6-100-4x (K3), $1.3 \mathrm{~kg}$; and C879-J2-4x (H10), $1.1 \mathrm{~kg}$, melons. have more rounded cotyledons, shorter internodes, thicker leaves, and more hairs. Fruit from tetraploid plants are smaller (one-third to one-half the size) than those of $2 x$ types, with stem and blossom scars three times larger than their $2 \mathrm{x}$ counterparts. Also, flowers and stomates of $4 x$ plants are one-third larger and rounder than those of $2 \mathrm{x}$ types, and pollen grains appear square instead of triangular (Nugent and Ray, 1992).

\section{Availability}

Small seed packets of these accessions are available on a pro-rata basis to breeders and other scientists upon request. Seed recipients are asked to give appropriate recognition of the germplasm source if it is used in developing a new germplasm, parental line, or cultiVar.

\section{Literature Cited}

Adelberg, J. 1993. Tetraploid melon from tissue culture and their triploid hybrids. PhD diss., Clemson Univ., Clemson, S.C.

Nugent, P.E. and D.T. Ray. 1992. Spontaneous tetraploidmelons. HortScience 27:47-50. 